\title{
A Rare Complication of Congenital Afibrinogenemia: Bone Cysts
}

\author{
Konjenital Afibrinojenemide Nadir Bir Komplikasyon: Kemik Kisti
}

Ali Fettah, Dilek Gürlek Gökçebay, Vildan Çulha, Neşe Yaralı, Bahattin Tunç, Namık Özbek

Ankara Children's Hematology and Oncology Research Hospital, Clinic of Pediatric Hematology, Ankara, Turkey

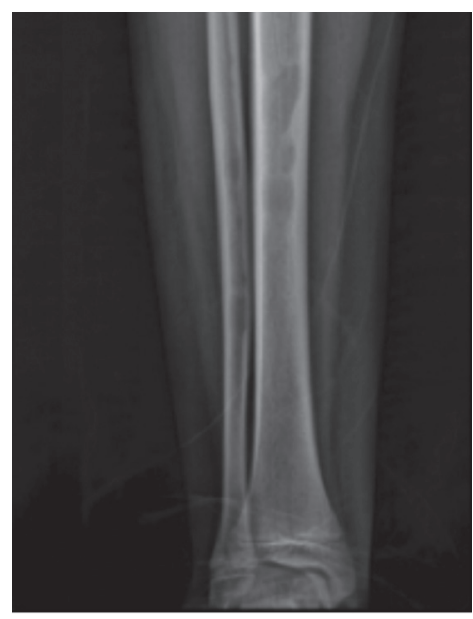

Figure 1. Direct radiography of the tibia.

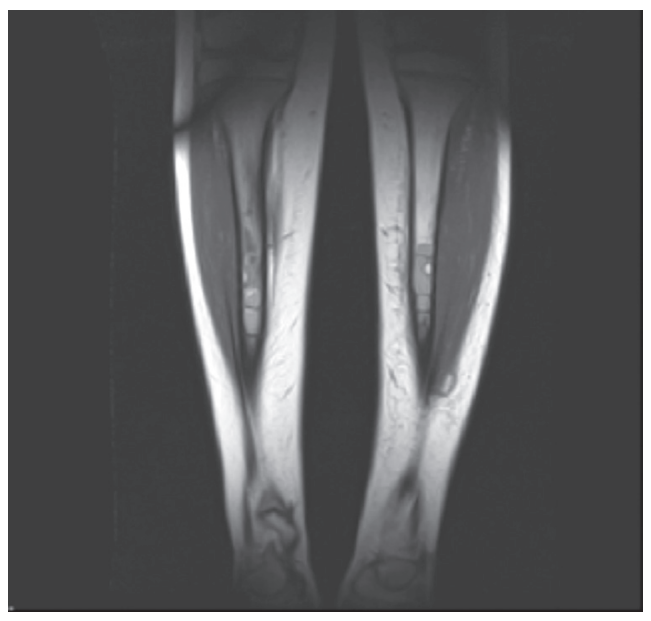

Figure 2. Magnetic resonance imaging of the lower extremities.
A 12-year-old male patient diagnosed with congenital afibrinogenemia presented to our center with pain, swelling, and ecchymosis in his leg after trauma. His past medical history revealed that he had been diagnosed with afibrinogenemia shortly after birth because of umbilical bleeding. Laboratory tests at admission revealed prolonged prothrombin time and activated partial thromboplastin time, and almost undetectable fibrinogen levels. A bone scan and radiograms of both legs showed multiple cystic lesions in the tibiae (Figure 1). Magnetic resonance imaging (MRI) of the legs also showed multicystic lesions with septae formation involving metaphyseal-diaphyseal junctions (Figure 2).

Bone cysts, one of the rare complications of afibrinogenemia, frequently appear in the contiguity of the cortex or trabeculae in the diaphysis of long bones, particularly the femora, tibiae, and humeri, and should be considered in patients who suffer rheumatic pains of the extremities [1,2]. Intraosseous hemorrhage, usually at the entrance of the nutrient artery, causes intraosseous cysts. Large cysts, especially in weightbearing bones, may cause pathological fractures $[2,3]$. Wholebody MRI might be useful to evaluate the lesions. We want to emphasize the importance of on-demand therapy and MRI in determining bone cysts. However, the role of secondary prophylaxis needs to be evaluated.

Keywords: Afibrinogenemia, Bone cysts, Child, Rare

Anahtar Sözcükler: Afibrinojenemi, Kemik kistleri, Çocuk, Nadir Informed Consent: Our patient's parent gave consent.

Conflict of Interest: The authors of this paper have no conflicts of interest, including specific financial interests, relationships, and/ or affiliations relevant to the subject matter or materials included.

\section{References}

1. Van Meegeren ME, De Rooy WJ, Schreuder HW, Brons PP. Bone cysts in patients with afibrinogenaemia: a literature review and two new cases. Haemophilia 2014;20:244-248.

2. Lagier $R$, Bouvier CA, Van Strijthem N. Skeletal changes in congenital fibrinogen abnormalities. Skeletal Radiol 1980;5:233-239.

3. Zenny JC, Chevrot A, Sultan Y, Godefroy D, Horreard P, Pallardy G. Intraosseus hemorrhagic lesions in congenital afibrinogenemia. J Radiol $1981 ; 62: 263-266$. 